\title{
Giant intracranial aneurysms of the posterior circulation and their relation to the brainstem: analysis of risk factors for neurological deficits
}

\author{
Pavlina Lenga, ${ }^{1}$ Christian Hohaus, MD, ${ }^{2}$ Bujung Hong, MD, ${ }^{3}$ Adisa Kursumovic, MD, ${ }^{4}$ \\ Nicolai Maldaner, MD, ${ }^{5}$ Jan-Karl Burkhardt, MD, ${ }^{5}$ Philippe Bijlenga, MD, ${ }^{6}$ \\ Daniel A. Rüfenacht, MD, ${ }^{7}$ Nils 0 . Schmidt, MD, ${ }^{8}$ Peter Vajkoczy, MD, ${ }^{1}$ and \\ Julius Dengler, MD, ${ }^{1}$ on behalf of the Giant Intracranial Aneurysm Registry Study Group
}

\begin{abstract}
1'Department of Neurosurgery, Charité-Universitaetsmedizin Berlin; 2Department of Neurosurgery, BG Hospital Bergmannstrost, Halle; ${ }^{3}$ Department of Neurosurgery, Hannover Medical School, Hannover; ${ }^{4}$ Department of Neurosurgery and Interventional Neuroradiology, DONAUISAR Klinikum Deggendorf, Germany; ${ }^{5}$ Department of Neurosurgery, University Hospital of Zurich; ${ }^{6}$ Department of Neurosurgery, University Hospital Geneva; 'Department of Neuroradiology, Clinic Hirslanden, Zurich, Switzerland; and ${ }^{8}$ Department of Neurosurgery, University Medical Center, Hamburg Eppendorf, Germany
\end{abstract}

OBJECTIVE Giant posterior circulation aneurysms (GPCirAs) usually cause substantial mass effect on the brainstem, which may lead to neurological deficits. So far, there has been no systematic investigation of factors associated with such deficits in GPCirA. The authors aim to examine the risk factors for cranial nerve deficit (CND), motor deficit, and disability in patients with GPCirA.

METHODS Using MR images obtained in 30 patients with unruptured GPCirA, the authors examined GPCirA volume, presence of hydrocephalus or partial thrombosis (PT) of the aneurysm, and the degree of brainstem displacement measured by the distance between the McRae line and the tip of the GPCirA $(\Delta \mathrm{MT})$. They evaluated associations between these factors and neurological deficits.

RESULTS Thirty GPCirAs in 30 patients were included. The prevalence of CNDs was $50 \%$. Patients with CNDs significantly differed from those without CNDs in terms of age (mean 51.0 years [SD 15.0 years] vs 69.0 years [SD 21.0 years], $p=0.01$ ) and in $\Delta \mathrm{MT}$ (median $50.7 \mathrm{~mm}$ [IQR 39.2-53.9 mm] vs $39.0 \mathrm{~mm}$ [IQR 32.3-45.9 mm], $p=0.02$ ). The prevalence of motor deficits was $33.3 \%$. Patients with motor deficits showed a larger $\triangle \mathrm{MT}$ (median $50.5 \mathrm{~mm}$ [IQR 40.8-54.6 mm]) compared with those without ( $\triangle \mathrm{MT}$ : median $39.1 \mathrm{~mm}$ [IQR 32.8-50.5 mm], $\mathrm{p}=0.04)$. GPCirA volume was larger in patients with poor modified Rankin Scale (mRS) scores (median $14.9 \mathrm{~cm}^{3}$ [IQR 8.6-18.7 cm $\mathrm{cm}^{3}$ ) than in those with $\mathrm{mRS}$ scores of $0-2$ (median $6.8 \mathrm{~cm}^{3}$ [IQR 4.4-11.7 $\left.\mathrm{cm}^{3}\right], p=0.03$ ). After adjusting for patient age and the occurrence of hydrocephalus or $\mathrm{PT}$, the authors found that higher degrees of disability were significantly associated with aneurysm volume (OR 1.13, 95\% Cl 1.0-1.3; $p=0.04$ ), but not with $\triangle \mathrm{MT}$. The occurrence of CND or motor deficit was not associated with any of the examined variables. There was no correlation between GPCirA volume and $\Delta M T\left(r_{s}=0.01, p=0.96\right)$. The prevalence of neurological deficits did not differ between GPCirA at the basilar apex, the basilar trunk, the vertebrobasilar junction, or the vertebral artery.

CONCLUSIONS In this study, the neurological condition of the patients was associated only with GPCirA volume and not with the degree of brainstem displacement, the occurrence of PT or hydrocephalus, or the exact location of the GPCirA. These findings highlight the clinical relevance of GPCirA volume and suggest that factors such as brainstem displacement or PT should play less of a role when finding arguments for or against treatment of GPCirA.

Clinical trial registration no.: NCT02066493 (clinicaltrials.gov)

https://thejns.org/doi/abs/10.3171/2018.4.JNS172343

KEYWORDS giant posterior circulation aneurysms; giant intracranial aneurysms; aneurysm volume; partially thrombosed aneurysm; McRae line; Evans index; cranial nerve deficit; brainstem; vascular disorders

ABBREVIATIONS $\mathrm{BI}=$ basilar invagination; $\mathrm{CN}=$ cranial nerve; $\mathrm{CND}=$ cranial nerve deficit; $\mathrm{EI}=$ Evans index; $\mathrm{GIA}=$ giant intracranial aneurysm; $\mathrm{GPCirA}=$ giant posterior circulation aneurysm; McRL = McRae line; $\mathrm{mRS}=$ modified Rankin Scale; $\mathrm{PT}=$ partial thrombosis; $\triangle \mathrm{MT}=$ distance between the McRL and highest tip of the GPCirA. SUBMITTED January 3, 2018. ACCEPTED April 2, 2018.

INCLUDE WHEN CITING Published online August 10, 2018; DOI: 10.3171/2018.4.JNS172343. 
$\mathrm{G}$ IANT posterior circulation aneurysms (GPCirA) are intracranial aneurysms with a diameter of at least $25 \mathrm{~mm}$ originating from the vertebral, basilar, cerebellar, or posterior cerebral artery. They are not only rare but are also associated with significantly higher morbidity and mortality than giant intracranial aneurysms in the anterior circulation, both during the course of natural history and after endovascular or surgical treatment. ${ }^{7,25}$ Since GPCirAs are located in the posterior fossa, their mass effect predominantly affects the brainstem and adjacent cranial nerves. ${ }^{2,27}$ They usually cause clinical symptoms such as cranial nerve deficits (CNDs), motor deficits, hydrocephalus, and different degrees of disability. ${ }^{2,13,16,18}$ They also frequently present with partial thrombosis (PT) and have various shapes. ${ }^{6,9}$ Previously published series describing brainstem compression by posterior circulation aneurysms either predominantly examined nongiant posterior circulation aneurysms or did not analyze GPCirA as a separate size category. ${ }^{15,27}$ So far, there has been no systematic analysis of factors associated with CNDs, motor deficits, or disability in patients with GPCirAs and no detailed description of different degrees of brainstem compression or displacement caused by these large lesions. In other diseases, such as basilar invagination (BI), brainstem compression or displacement has been studied and correlated to clinical findings. ${ }^{11,20} \mathrm{BI}$ is defined as the protrusion of the odontoid tip of more than $5 \mathrm{~mm}$ above the McRae line (McRL), which connects the clivus to the opisthion at the cranial base. ${ }^{4}$ Once the odontoid tip extends into the foramen magnum, compression and displacement of the brainstem with ensuing neurological deficits may occur. ${ }^{11,20}$

Since GPCirAs usually compress and displace the brainstem, much like the odontoid tip does in BI, certain clinical and diagnostic paradigms valid in BI may be transferrable to GPCirAs. We designed a study to examine potential associations between GPCirA characteristics and the occurrence of CND, motor deficit, disability, and hydrocephalus. We also aimed to test the hypothesis that neurological deficits are associated with GPCirA volume and the amount of brainstem displacement.

\section{Methods \\ GIA Registry Imaging Database}

All clinical and imaging data for this analysis were retrospectively collected from the giant intracranial aneurysm (GIA) registry's prospective database. The GIA registry is an international observational study collecting clinical and imaging data exclusively for GIAs in Europe, the US, and Japan. The ethics committee of the Charité Berlin and the ethics committees of each participating center approved the collection of data. Each patient or next of kin gave consent to participation. The GIA registry is listed at clinicaltrials.gov under the registration no. NCT02066493. Patients were included in this specific study if they were diagnosed with a GIA in the posterior circulation (diameter $\geq 25 \mathrm{~mm}$ ) and their pretreatment MRI study was available in the imaging database.

\section{Imaging Analysis, Volumetry, and GIA Characteristics}

We used MRI with time-of-flight sequences and T2- weighted images and digital subtraction angiography for radiographic analysis. PT was defined as the difference between the perfused GPCirA volume as seen on DSA and the GPCirA volume on MRI. We quantified GPCirAs by measuring their volume using iPlan Cranial software (Brainlab). For this, the circumference of the GPCirA was marked manually using the mouse cursor on each slice of the T2-weighted images. All measurements were conducted at the GIA registry's coordinating center at the Charité Berlin by 2 experienced examiners (J.D. and P.L.). Similar to previous studies on BI, we measured brainstem displacement away from the cranial base on midsagittal T2-weighted imaging using the distance between the highest tip of the GPCirA and the McRae line (McRL), which connects the basion to the opisthion at the cranial base, as shown in Fig. 1.4,11 This distance is referred to as $\Delta \mathrm{MT}$. Hydrocephalus was measured on images, as previously described, using the Evans index (EI), which is defined as the ratio of the transverse diameter of the frontal horns of the lateral ventricles to the maximum inner transverse diameter of the skull at the same axial level on T2-weighted images. ${ }^{8,23}$ According to international guidelines, an EI greater than 0.3 is an indicator for hydrocephalus. ${ }^{23} \mathrm{We}$ also grouped the GPCirA according to the vessel segments involved, using the following categories: basilar apex, basilar trunk, vertebrobasilar junction, and vertebral artery.

\section{Clinical Data}

Clinical data included patient age, sex, modified Rankin Scale (mRS) score, and the presence of CND or motor deficit. According to International Neuromodulation Society standards, motor deficit was defined as partial or total loss of function of a body part, usually a limb or limbs, resulting in muscle weakness, poor stamina, lack of muscle control, or total paralysis. ${ }^{12}$ The level of disability was classified as mild (mRS scores $0-2)$ or severe (mRS scores $3-5) .^{24}$

\section{Statistical Analysis}

All statistical analyses were performed using IBM SPSS software (version 24, IBM Corp.). Since previous studies showed that there is high interobserver reliability in measuring volumes of GIAs, data on interobserver reliability are not presented separately. ${ }^{26}$ We examined normal distribution of data by using the Shapiro-Wilk test. The Mann-Whitney U-test or chi-square test was used for the comparison of the baseline characteristic data. Since all variables, except for patient age, were not normally distributed, their values are presented as medians with IQR, while patient age is presented using means and SD. The relationship between aneurysm volume and the distance between the McRae line and the highest tip of the aneurysms was tested using Spearman correlation. Differences in prevalence between GPCirA locations within the posterior circulation (basilar apex, basilar trunk, vertebrobasilar junction, and vertebral artery) were examined using the chi-square test. To investigate associations, we used separate regression analysis models with dependent variables CND and motor deficit (each using binary regression 

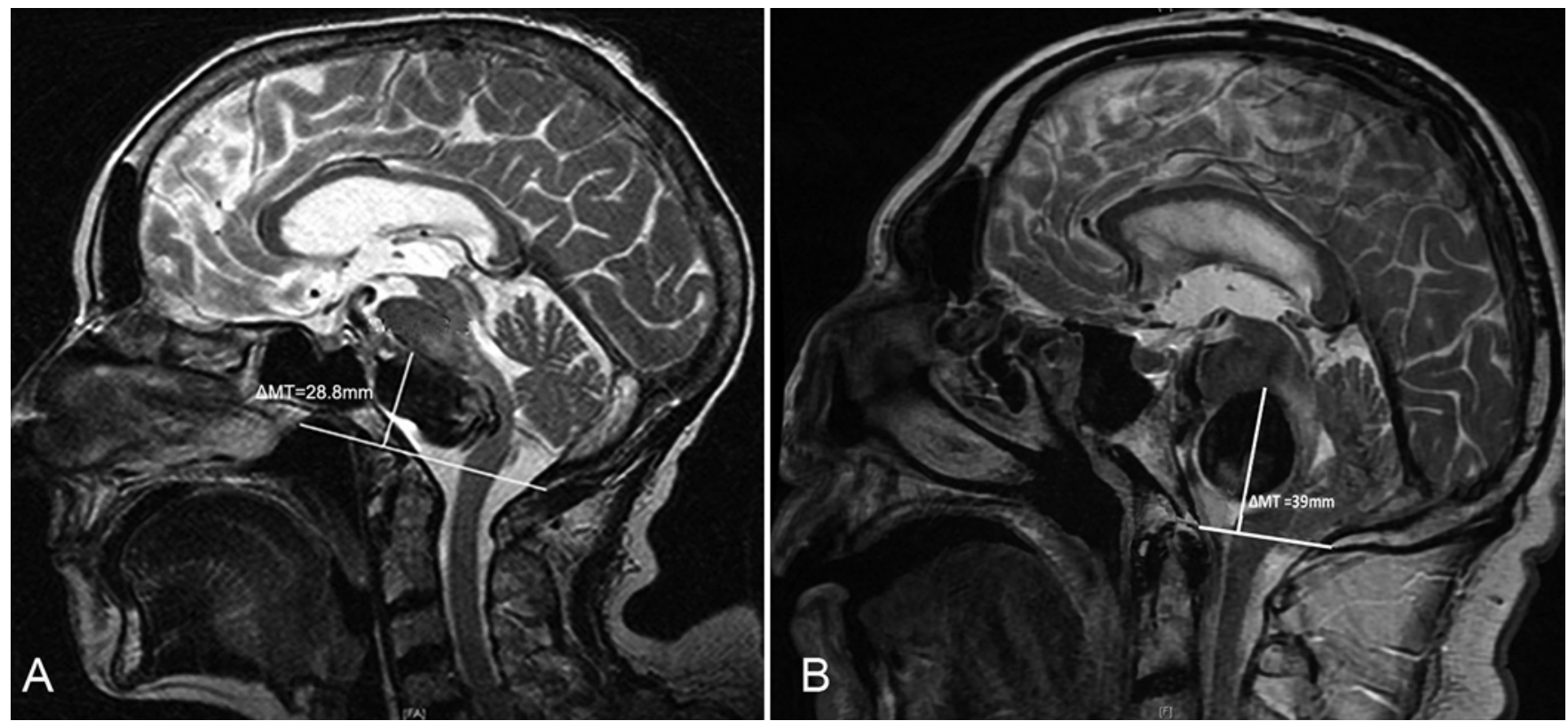

FIG. 1. MR images showing 2 examples of the quantification of brainstem displacement by measuring the distance between the McRae line and the highest tip of the aneurysm at a $90^{\circ}$ angle from the McRae line.

analysis) and mRS score (ordinal regression analysis). In each model, the independent variables were patient age, $\triangle \mathrm{MT}$, GPCirA volume, and the occurrence of hydrocephalus according to EI. In the regression model examining associations with mRS score, we also used the occurrence of PT as an independent variable.

\section{Results}

\section{Patient and Aneurysm Characteristics}

We included 30 cases of unruptured GPCirAs in 30 patients who were enrolled in the GIA registry between January 2009 and March 2017 at 7 participating centers (Table 1). Mean age was 60.6 years (SD 12.8), and the majority of patients were male $(25 / 30,83.3 \%)$. The median $\triangle \mathrm{MT}$ was $41.1 \mathrm{~mm}$ (IQR 34.6-51.0 mm), and the median aneurysm volume $7.9 \mathrm{~cm}^{3}$ (IQR $5.2-14.3 \mathrm{~cm}^{3}$ ). We found no correlation between GPCirA volume and $\Delta \mathrm{MT}\left(\mathrm{r}_{\mathrm{s}}=0.01, \mathrm{p}=\right.$ 0.96). A CND was present in $50.0 \%$ of all GPCirAs, a motor deficit was found in $33.3 \%$, and $10.0 \%$ were completely asymptomatic. Another $20.0 \%$ of all patients showed only very mild disability (mRS score 1 ) without any CND or motor deficit. Table 2 demonstrates differences between patients with neurological symptoms and those without, according to CND, motor deficit, and mRS score.

\section{CND Groups}

In patients with $\mathrm{CND}$, the median $\triangle \mathrm{MT}$ was significantly larger $(50.7 \mathrm{~mm}$, IQR $39.2-53.9 \mathrm{~mm})$ than in patients without CND (39.0 mm [IQR 32.3-45.9 mm], $\mathrm{p}=$ $0.02)$. Also, patients with CND were significantly younger (51.0 years [SD 15.0 years] vs 69.0 years [SD 21.0 years]; $\mathrm{p}=0.01$ ). There was no difference between the $2 \mathrm{CND}$ groups in terms of sex, aneurysm volumes, or diameters and the prevalence of PT or hydrocephalus.

\section{Motor Deficit Groups}

Cases with motor deficit showed significantly larger $\Delta$ MTs (50.5 mm [IQR 40.8-54.6 mm]) compared to patients without motor deficit (39.1 mm [IQR 32.8-50.5 $\mathrm{mm}], \mathrm{p}=0.04)$. No significant differences between groups were observed for GPCirA volume or diameter, patient age, sex, and the prevalence of PT or hydrocephalus.

TABLE 1. Summary of patient and aneurysm characteristics

\begin{tabular}{lc}
\hline & Value \\
\hline No. of GPCirAs & 30 \\
\hline Mean patient age (SD), yrs & $60.6(12.8)$ \\
\hline Male sex, $\mathrm{n}(\%)$ & $25(83.3 \%)$ \\
\hline CND, $\mathrm{n}(\%)$ & $15(50.0 \%)$ \\
\hline Motor deficit, $\mathrm{n}(\%)$ & $10(33.3 \%)$ \\
\hline Mean mRS score (SD) & $1.8(2.0)$ \\
\hline 0 (asymptomatic), $\mathrm{n}(\%)$ & $3(10.0 \%)$ \\
\hline $1-2$ (mild disability), $\mathrm{n}(\%)$ & $19(63.3 \%)$ \\
\hline $3-5$ (severe disability), $\mathrm{n}(\%)$ & $8(26.7 \%)$ \\
\hline Hydrocephalus, $\mathrm{n}(\%)$ & $17(56.7 \%)$ \\
\hline Median $\Delta$ MT (IQR), mm & $41.1(34.6-51.0)$ \\
\hline Median GPCirA vol (IQR), cm ${ }^{3}$ & $7.9(5.2-14.3)$ \\
\hline Median GPCirA diameter (IQR), $\mathrm{mm}$ & $35.3(28.3-39.6)$ \\
\hline Prevalence of PT, $\mathrm{n}(\%)$ & $24(80.0 \%)$ \\
\hline GPCirA location, $\mathrm{n}(\%)$ & \\
\hline Basilar apex & $4(13.3 \%)$ \\
\hline Basilar trunk & $9(30.0 \%)$ \\
\hline Vertebrobasilar junction & $12(40.0 \%)$ \\
\hline Vertebral artery & $5(16.7 \%)$ \\
\hline
\end{tabular}


TABLE 2. Differences between patient groups

\begin{tabular}{|c|c|c|c|c|c|c|c|c|c|}
\hline & Patients w/ CND & $\begin{array}{l}\text { Patients w/o } \\
\text { CND }\end{array}$ & $\begin{array}{c}p \\
\text { Value }\end{array}$ & $\begin{array}{l}\text { Patients w/ } \\
\text { Motor Deficit }\end{array}$ & $\begin{array}{l}\text { Patients w/o } \\
\text { Motor Deficit }\end{array}$ & $\begin{array}{c}p \\
\text { Value }\end{array}$ & $\begin{array}{l}\text { Patients w/ mRS } \\
\text { Scores } 0-2\end{array}$ & $\begin{array}{l}\text { Patients w/ mRS } \\
\text { Scores 3-5 }\end{array}$ & $\begin{array}{c}p \\
\text { Value }\end{array}$ \\
\hline No. of patients & 15 & 15 & & 10 & 20 & & 22 & 8 & \\
\hline $\begin{array}{l}\text { Mean age (SD), } \\
\text { yrs }\end{array}$ & $51(15.0)$ & $69(21.0)$ & 0.01 & $53.3(26.5)$ & $63.9(20.8)$ & 0.08 & $60.5(20.8)$ & $60.9(32.0)$ & 0.98 \\
\hline $\begin{array}{l}\text { Sex, male, } n \\
(\%)\end{array}$ & $14(93.3)$ & $11(73.3)$ & 0.14 & $8(80.0)$ & $17(85.0)$ & 0.73 & $19(86.4)$ & $6(75.0)$ & 0.46 \\
\hline $\begin{array}{l}\text { Prevalence of } \\
\text { hydrocepha- } \\
\text { lus, } \mathrm{n}(\%)\end{array}$ & $7(46.7)$ & $10(66.7)$ & 0.27 & $7(70.0)$ & $10(50.0)$ & 0.30 & $10(45.5)$ & $7(87.5)$ & 0.09 \\
\hline $\begin{array}{r}\text { Median } \Delta \mathrm{MT} \\
(\mathrm{IQR}), \mathrm{mm}\end{array}$ & $50.7(39.2-53.9)$ & $39.0(32.3-45.9)$ & 0.02 & $50.5(40.8-54.6)$ & $39.1(32.8-50.5)$ & 0.04 & $43.5(34.8-51.0)$ & $41.1(32.3-65.7)$ & 0.82 \\
\hline $\begin{array}{l}\text { Median GPCirA } \\
\text { vol (IQR), } \\
\mathrm{cm}^{3}\end{array}$ & $6.7(4.0-10.9)$ & $8.6(6.6-17.4)$ & 0.16 & $6.8(5.3-12.5)$ & $7.9(4.7-14.7)$ & 0.88 & $6.8(4.4-11.7)$ & $14.9(8.6-18.7)$ & 0.03 \\
\hline $\begin{array}{l}\text { Median GPCirA } \\
\text { diameter } \\
\text { (IQR), mm }\end{array}$ & $34.7(29.0-38.3)$ & $36.5(28.3-40.6)$ & $>0.99$ & $35.6(31.2-42.7)$ & $34.4(27.6-39.2)$ & 0.42 & $33.2(27.2-37.8)$ & $38.8(35.2-45.6)$ & 0.04 \\
\hline $\begin{array}{c}\text { Prevalence of } \\
\text { PT, } n(\%)\end{array}$ & $13(86.7)$ & $11(73.3)$ & 0.36 & $9(90.0)$ & $15(75.0)$ & 0.33 & $16(72.7)$ & $8(100.0)$ & 0.10 \\
\hline
\end{tabular}

Boldface type indicates statistical significance.

\section{mRS Groups}

Patients with poor mRS scores had significantly larger aneurysm volumes (median $14.9 \mathrm{~cm}^{3}$ [IQR $\left.8.6-18.7 \mathrm{~cm}^{3}\right]$ ) and diameters (median $38.8 \mathrm{~mm}$ [IQR 35.2-45.6 mm]) than patients with good mRS scores (median volume: 6.8 $\mathrm{cm}^{3}$ [IQR 4.4-11.7 $\mathrm{cm}^{3}$ ], $\mathrm{p}=0.03$; median diameter: 33.2 $\mathrm{mm}$ [IQR 27.2-37.8 mm]; $\mathrm{p}=0.04)$. There were no significant differences between groups regarding any of the other examined variables.

\section{Associations Between Neurological Deficits and GPCirA Location, $\triangle \mathrm{MT}$, GPCirA Volume, and Occurrence of Hydrocephalus}

We found no difference between GPCirA locations when comparing prevalences of neurological deficits (Table 3). Table 4 describes associations between neurological deficits and $\triangle \mathrm{MT}$, GPCirA volumes, and the presence of hydrocephalus. Poor clinical condition (mRS scores 3-5) was significantly associated with aneurysm volume (OR $1.13,95 \%$ CI $1.00-1.27 ; \mathrm{p}=0.04$ ), but not with $\Delta \mathrm{MT}$ or the occurrence of hydrocephalus. For CND and motor deficit, we found no associations with any of the examined factors.

\section{Discussion}

The main result of this analysis is that in our patient cohort, larger GPCirA volume was significantly associated with higher degrees of disability but not with the prevalence of CNDs or motor deficits. The degree of brainstem displacement away from the cranial base was not a significant risk factor for the occurrence of CNDs, motor deficits, or different degrees of disability. CNDs, motor deficits, and hydrocephalus were frequent phenomena with prevalences of $50 \%, 33 \%$, and $57 \%$, respectively.

The premise of our study was that certain paradigms relevant to the diagnosis and clinical presentation of $\mathrm{BI}$ may be transferable to GPCirAs. Cronin et al. described that the linear measurement of the distance between the odontoid tip and the McRL is the most accurate tool to confirm the diagnosis of BI. ${ }^{4}$ They also defined a distance of at least $5 \mathrm{~mm}$ between the McRL and the tip of the odontoid as indicative of BI. Goel described 22 cases of BI with distances between the McRL and the odontoid tip ranging between 3 and $19 \mathrm{~mm} .{ }^{11}$ The majority of his patients presented with motor deficit, neck pain, and sensory problems. Only in 9\% did Goel observe CND. In another series of 17 patients with $\mathrm{BI}$, the median distance between

TABLE 3. Prevalence of neurological deficits in relation to GPCirA location

\begin{tabular}{lccccc}
\hline & \multicolumn{4}{c}{ GPCirA Location } & $p$ \\
\cline { 2 - 5 } & Basilar Apex $(n=4)$ & Basilar Trunk $(n=9)$ & Vertebrobasilar Junction $(n=12)$ & Vertebral Artery $(n=5)$ & Value \\
\hline CND & 75.0 & 55.6 & 33.3 & 60.0 & 0.45 \\
\hline Motor deficit & 25.0 & 55.6 & 25.0 & 20.0 & 0.41 \\
\hline mRS score 0-2 & 75.0 & 77.8 & 66.7 & 80.0 & 0.92 \\
\hline
\end{tabular}

Values are percentages unless specified otherwise. 
TABLE 4. Associations between neurological deficits and $\triangle M T$, GPCirA volumes, and the occurrence of hydrocephalus

\begin{tabular}{lll}
\hline & OR $(95 \% \mathrm{Cl})$ & p Value \\
\hline CND & & \\
\hline$\Delta \mathrm{MT}$ & $1.04(0.96-1.13)$ & 0.31 \\
\hline GPCirA vol & $0.90(0.76-1.05)$ & 0.18 \\
\hline Patient age & $0.92(0.84-1.01)$ & 0.08 \\
\hline Occurrence of hydrocephalus & $0.69(0.07-6.49)$ & 0.74 \\
\hline Motor deficit & & \\
\hline$\Delta$ MT & $1.03(0.89-1.14)$ & 0.58 \\
\hline GPCirA vol & $0.96(0.83-1.10)$ & 0.56 \\
\hline Patient age & $0.94(0.86-1.03)$ & 0.17 \\
\hline Occurrence of hydrocephalus & $5.02(0.46-55.1)$ & 0.19 \\
\hline mRS & & \\
\hline$\Delta$ MT & $1.39(0.97-1.11)$ & 0.34 \\
\hline GPCirA vol & $1.13(1.00-1.27)$ & 0.04 \\
\hline Patient age & $1.00(0.93-1.08)$ & 0.99 \\
\hline Occurrence of hydrocephalus & $1.13(0.20-6.35)$ & 0.89 \\
\hline Occurrence of PT & $0.11(0.01-1.17)$ & 0.07 \\
\hline Bof
\end{tabular}

Boldface type indicates statistical significance.

the McRL and the odontoid tip was $5.8 \mathrm{~mm}$, with the largest distance being $25.7 \mathrm{~mm} .{ }^{3}$ Here, the most frequent symptoms were motor deficit $(96 \%)$, neck pain $(62 \%)$, and unsteady gait (52\%). In our cohort of GPCirAs, the median $\triangle \mathrm{MT}$ was $41.1 \mathrm{~mm}$, which surpasses the pathological threshold of $5 \mathrm{~mm}$ (i.e., the threshold set for BI) by $36.1 \mathrm{~mm}$, and ranges higher than the distances described in the aforementioned series on BI. The fact that, in our cohort, the amount of brainstem displacement away from the cranial base was not associated with the occurrence of any neurological deficits-while aneurysm volume wassuggests that the actual craniodorsal displacement of the brainstem by the GPCirA and GPCirA volume seem to be 2 separate, nonexchangeable risk factors for morbidity. This is further supported by both of these variables not showing any correlation to each other in our patient cohort.

So far, there has not been an analysis of risk factors for neurological deficits exclusively for giant aneurysms of the posterior circulation. Previously published reports on the effects of brainstem compression by posterior circulation aneurysms either only included few aneurysms of giant size or did not evaluate giant size as a separate category. ${ }^{15,27}$ In a series of 52 vertebrobasilar aneurysms with a median diameter of $10.0 \mathrm{~mm}$ (range $4.0-35.0 \mathrm{~mm}$ ), aneurysm size was associated with the occurrence of compressive brainstem symptoms, which were not described more closely. ${ }^{15}$ Similarly, a different series of 50 posterior circulation aneurysms categorized sizes only as $\leq 7 \mathrm{~mm}$ and $>7 \mathrm{~mm}$, and does not describe how many were $>25$ $\mathrm{mm} .{ }^{27} \mathrm{In}$ that series, a deterioration in the $\mathrm{mRS}$ score over time was not associated with aneurysm size or different degrees of radiographic brainstem compression. Our findings may be in contrast to those of those 2 studies, mainly since we exclusively examined giant aneurysms, which exert larger mass effects on their surroundings than nonGIAs. Another contrast is that we adjusted our results for the effects of age and hydrocephalus, which is a significantly more likely comorbidity in GPCirAs than in their nongiant counterparts.

The fact that in our series different degrees of brainstem displacement away from the cranial base were not associated with the prevalence of CND is somewhat surprising, especially when considering the anatomical distribution of cranial nerve nuclei within the brainstem. The nuclei of cranial nerves (CNs) IX and X and some sensory nuclei for CNs V and VIII are located at the level of the medulla oblongata. The pontomedullary junction harbors the nuclei of CNs VI, VII, and VIII, and the midbrain tegmentum harbors the nuclei of CNs III and VI. ${ }^{22}$ In our series, we observed significant displacement of all of these parts of the brainstem, with different degrees of displacement for different brainstem sections. Our findings suggest that the cranial nerve nuclei and the cranial nerves themselves seem to be able to adjust to a most likely slowly increasing craniodorsal displacement of the brainstem caused by a GPCirA. Interestingly, aneurysm volume significantly predicted patient disability as measured by mRS score, while the degree of brainstem displacement was not a predictor of disability. The observation that GPCirA volume causes disability is in line with previously published studies on BI, in which the volume of the mass effect on the brainstem caused by odontoid protrusion was surgically reduced, which resulted in improvement in disability. ${ }^{3,5}$ Similar findings were made in studies of patients with posterior fossa tumors. In a series of 75 meningiomas involving the clivus, patients with larger tumors were at higher risk of disability. ${ }^{21}$ Here, the majority of the tumors were larger than $2.5 \mathrm{~cm}$ in diameter and therefore of sizes similar to GPCirAs. Almefty et al. described similar results for petroclival meningiomas, where patient disability significantly improved after surgical reduction of tumor volume. ${ }^{1}$

Interestingly, we observed that CNDs occurred more frequently in younger patients with GPCirAs. This may be explained by the fact that the brain's volume shrinks by approximately $5 \%$ per decade in patients older than 40 years. ${ }^{19}$ This age-related brain atrophy may create additional space that may be utilized by neighboring structures to evade some of the mass effect caused by the GPCirA so that some of the stress on the cranial nerve nuclei may be relieved.

It is important to stress that, in our series, the occurrence of hydrocephalus was not a risk factor for neurological deficits. Still, hydrocephalus was present in more than half of our cases, suggesting that most patients with GPCirAs may experience significant disruption of CSF flow caused by the aneurysm's mass effect. We also found that neurological deficits were equally distributed among the different GPCirA locations within the posterior circulation, ranging from the vertebral artery up to the basilar apex. This highlights that all locations within the posterior circulation should be viewed as equally critical for GPCirA morbidity.

Even though PT was quite frequent in our series, it was not associated with the prevalence of neurological 
deficits. The exact pathophysiological role of PT in intracranial aneurysms remains controversial. While some authors found PT to be associated with greater rupture and growth rates, ${ }^{17}$ others have described it as preventing aneurysm rupture as part of remodeling processes within the aneurysm wall, which seem to have a protective effect. ${ }^{10,14}$

Almost one-third of our patient cohort was either completely asymptomatic or displayed only mild disability without any CND or motor deficit. Since both endovascular and surgical management of GPCirAs are associated with significantly worse outcomes compared with those of giant intracranial aneurysms in the anterior circulation, we feel that in patients with no or only very mild impairment, conservative management with regular follow-up imaging ought to be considered. ${ }^{25}$ As stated by the authors of the International Study of Unruptured Intracranial Aneurysms (ISUIA), any treatment decisions for GPCirAs should be discussed in depth with each patient due to the high risk of treatment-associated disability. ${ }^{25}$ We feel that our findings are clinically relevant since they may help find arguments for or against treatment, especially since we showed that GPCirA volume seems to be the only significant factor in predicting neurological deficits. In contrast, frequently discussed characteristics like the degree of brainstem displacement away from the cranial base, GPCirA location, or even the occurrence of PT or radiographically diagnosed hydrocephalus may not be associated with the patient's neurological condition.

The main strength of our study is that it is the first systematic investigation of the relationship between GPCirA morphology and the occurrence of CNDs, motor deficits, and disability. However, some limitations do exist. First of all, at this point we do not present follow-up data over time or after treatment. We will be able to present such data in the future, as the registry is still ongoing. However, we feel that the series of baseline, pretreatment data presented here is of significant scientific value, since it is the first of its kind in this rare and high-risk disease condition. Furthermore, we examined a relatively small cohort of patients $(n=30)$. However, since GPCirAs, unlike nongiant posterior circulation aneurysms, are rare entities, a multicenter approach was necessary to acquire even 30 cases. Also, there is a risk of selection bias since patients with neurological deficits may have been more likely to be diagnosed and therefore entered into the registry than asymptomatic patients. Furthermore, we did not examine the potential clinical relevance of lateral versus medial displacement of the brainstem in this analysis. Another limitation is that we only used those GPCirAs from the GIA registry for which imaging data were available in our imaging database. Since the submission of imaging is not required by the registry, some GPCirAs in the clinical database of the registry could not be included in this analysis. Also, one may argue that the highest aneurysm tip on midsagittal MRI is a rather random indicator of brainstem displacement. However, in BI, the distance between the McRL and the tip of the odontoid on midsagittal imaging is an established parameter, so we feel that transferring this mode of measurement to GPCirA seems reasonable.

\section{Conclusions}

In this cohort of patients with GPCirA, there was no correlation between GPCirA volume and the degree of brainstem displacement away from the cranial base. Neurological deficits were associated only with GPCirA volume but not with brainstem displacement away from the cranial base, the occurrence of PT or hydrocephalus, or the exact location of the GPCirA within the posterior circulation. Our findings highlight the clinical relevance of GPCirA volume and suggest that factors like brainstem displacement or partial thrombosis should play less of a role when finding arguments for or against the treatment of GPCirAs.

\section{References}

1. Almefty R, Dunn IF, Pravdenkova S, Abolfotoh M, Al-Mefty $\mathrm{O}$ : True petroclival meningiomas: results of surgical management. J Neurosurg 120:40-51, 2014

2. Bhogal P, Pérez MA, Ganslandt O, Bäzner H, Henkes H, Fischer S: Treatment of posterior circulation non-saccular aneurysms with flow diverters: a single-center experience and review of 56 patients. J Neurointerv Surg 9:471-481, 2017

3. Chandra PS, Kumar A, Chauhan A, Ansari A, Mishra NK, Sharma BS: Distraction, compression, and extension reduction of basilar invagination and atlantoaxial dislocation: a novel pilot technique. Neurosurgery 72:1040-1053, 2013

4. Cronin CG, Lohan DG, Mhuircheartigh JN, Meehan CP, Murphy JM, Roche C: MRI evaluation and measurement of the normal odontoid peg position. Clin Radiol 62:897-903, 2007

5. Dasenbrock HH, Clarke MJ, Bydon A, Sciubba DM, Witham TF, Gokaslan ZL, et al: Endoscopic image-guided transcervical odontoidectomy: outcomes of 15 patients with basilar invagination. Neurosurgery 70:351-360, 2012

6. Dengler J, Maldaner N, Bijlenga P, Burkhardt JK, Graewe A, Guhl S, et al: Quantifying unruptured giant intracranial aneurysms by measuring diameter and volume--a comparative analysis of 69 cases. Acta Neurochir (Wien) 157:361-368, 2015

7. Drake CG, Peerless SJ: Giant fusiform intracranial aneurysms: review of 120 patients treated surgically from 1965 to 1992. J Neurosurg 87:141-162, 1997

8. Evans WA Jr: An encephalographic ratio for estimating ventricular enlargement and cerebral atrophy. Arch Neurol Psychiatry 47:931-937, 1942

9. Flemming KD, Wiebers DO, Brown RD Jr, Link MJ, Huston J III, McClelland RL, et al: The natural history of radiographically defined vertebrobasilar nonsaccular intracranial aneurysms. Cerebrovasc Dis 20:270-279, 2005

10. Frösen J, Piippo A, Paetau A, Kangasniemi M, Niemelä M, Hernesniemi J, et al: Remodeling of saccular cerebral artery aneurysm wall is associated with rupture: histological analysis of 24 unruptured and 42 ruptured cases. Stroke 35:22872293, 2004

11. Goel A: Basilar invagination, Chiari malformation, syringomyelia: a review. Neurol India 57:235-246, 2009

12. Henderson JM: Motor impairment. Neuromodulation.com. April 2, 2012. (http://www.neuromodulation.com/motorimpairment) [Accessed July 25, 2018]

13. Kolić Z, Kukuljan M, Vukas D, Bonifačić D, Vrbanec K, Franić IK: Locked-in syndrome in a patient with acute obstructive hydrocephalus, caused by large unruptured aneurysm of the basilar artery (BA). Br J Neurosurg 31:738-740, 2017

14. Krings T, Alvarez H, Reinacher P, Ozanne A, Baccin CE, Gandolfo C, et al: Growth and rupture mechanism of partial- 
ly thrombosed aneurysms. Interv Neuroradiol 13:117-126, 2007

15. Mangrum WI, Huston J III, Link MJ, Wiebers DO, McClelland RL, Christianson TJ, et al: Enlarging vertebrobasilar nonsaccular intracranial aneurysms: frequency, predictors, and clinical outcome of growth. J Neurosurg 102:72-79, 2005

16. Nakayama Y, Tanaka A, Kumate S, Tomonaga M, Takebayashi S: Giant fusiform aneurysm of the basilar artery: consideration of its pathogenesis. Surg Neurol 51:140-145, 1999

17. Nasr DM, Brinjikji W, Rouchaud A, Kadirvel R, Flemming $\mathrm{KD}$, Kallmes DF: Imaging characteristics of growing and ruptured vertebrobasilar non-saccular and dolichoectatic aneurysms. Stroke 47:106-112, 2016

18. Oishi H, Shimizu T, Nakai K, Miyajima M, Arai H: Successful treatment of a thrombosed posterior cerebral artery aneurysm causing obstructive hydrocephalus. J Clin Neurosci 15:199-202, 2008

19. Peters R: Ageing and the brain. Postgrad Med J 82:84-88, 2006

20. Pinter NK, McVige J, Mechtler L: Basilar invagination, basilar impression, and platybasia: clinical and imaging aspects. Curr Pain Headache Rep 20:49, 2016

21. Sekhar LN, Swamy NK, Jaiswal V, Rubinstein E, Hirsch WE Jr, Wright DC: Surgical excision of meningiomas involving the clivus: preoperative and intraoperative features as predictors of postoperative functional deterioration. J Neurosurg 81:860-868, 1994

22. Smith LH, DeMyer WE: Anatomy of the brainstem. Semin Pediatr Neurol 10:235-240, 2003

23. Toma AK, Holl E, Kitchen ND, Watkins LD: Evans' index revisited: the need for an alternative in normal pressure hydrocephalus. Neurosurgery 68:939-944, 2011

24. Weisscher N, Vermeulen M, Roos YB, de Haan RJ: What should be defined as good outcome in stroke trials; a modified Rankin score of 0-1 or 0-2? J Neurol 255:867-874, 2008

25. Wiebers DO, Whisnant JP, Huston J III, Meissner I, Brown
RD Jr, Piepgras DG, et al: Unruptured intracranial aneurysms: natural history, clinical outcome, and risks of surgical and endovascular treatment. Lancet 362:103-110, 2003

26. Wostrack M, Mielke D, Kato N, Guhl S, Schmidt NO, Maldaner N, et al: Interobserver variability in the characterization of giant intracranial aneurysms with special emphasis on aneurysm diameter and shape. Acta Neurochir (Wien) 157:1859-1865, 2015

27. Xu DS, Levitt MR, Kalani MYS, Rangel-Castilla L, Mulholland CB, Abecassis IJ, et al: Dolichoectatic aneurysms of the vertebrobasilar system: clinical and radiographic factors that predict poor outcomes. J Neurosurg 128:560-566, 2018

\section{Disclosures}

The Giant Intracranial Aneurysm Registry is funded by the Center for Stroke Research-Berlin (Grant No. CS-2009-12) to J.D., the coordinating officer of the registry. This financial support exclusively funds the maintenance of the internet-based database.

\section{Author Contributions}

Conception and design: Dengler, Lenga, Vajkoczy. Acquisition of data: all authors. Analysis and interpretation of data: Dengler, Lenga. Drafting the article: Dengler, Lenga. Critically revising the article: all authors. Reviewed submitted version of manuscript: all authors. Approved the final version of the manuscript on behalf of all authors: Dengler. Statistical analysis: Dengler, Lenga. Administrative/technical/material support: Dengler, Hohaus, Hong,

Kursumovic, Maldaner, Burkhardt, Bijlenga, Rüfenacht, Schmidt, Vajkoczy. Study supervision: Dengler.

\section{Correspondence}

Julius Dengler: Charité-Universitaetsmedizin Berlin, Germany. julius.dengler@charite.de. 